\title{
The underrated prevalence of depression in Japanese patients with rheumatoid arthritis - evidence from a Nationwide survey in Japan
}

\author{
Rosarin Sruamsiri ${ }^{1,2}$, Yuko Kaneko ${ }^{3}$ and Jörg Mahlich ${ }^{1,4^{*}}$ (D)
}

\begin{abstract}
Background: To determine the prevalence of depression among Japanese people with rheumatoid arthritis (RA) and explore the relationships between depression and an array of variables.

Methods: Nation-wide, cross-sectional online survey $(n=500)$ of people with RA including the Patient Health Questionnaire (PHQ-9) to measure the presence and severity of depressive symptoms were performed.

Results: While only 5\% of the population studied had been officially diagnosed with depression, 35\% had PHQ-9 scores indicating depression was present. People with RA are more likely to experience depression if they are younger, have greater functional impairment, or whose treatment regimen includes pain medications not biologic agents.

Conclusions: It is a potential risk of under-diagnosis and under-reporting of depression in Japanese people with RA. People with RA are more likely to experience depression if they are younger, have greater functional impairment, or whose treatment regimen includes pain medications without biologic drugs.
\end{abstract}

Keywords: Depression, Rheumatoid arthritis, Prevalence, PHQ-9

\section{Background}

Significant evidence in the scholarly literature suggests that depression is a common comorbidity among patients with rheumatoid arthritis (RA) [1-3]. The prevalence of depression varies significantly between different studies, but by some estimates occurs in as many as $42 \%$ of RA patients [4]. A meta-analysis of 72 studies involving 13,189 people with RA revealed that from 14.8 to $38.8 \%$ of people with RA receive a diagnosis of a major depressive disorder [5].

Depression in RA is a risk factor not only for suicidal ideation [6] but for cardiovascular disease [7], myocardial infarction [8], and mortality [9]. Patients with RA are at greater risk of experiencing anxiety, depression, and low selfesteem, with higher levels of associated mortality and suicide

\footnotetext{
* Correspondence: joerg.mahlich@gmail.com

${ }^{1}$ Health Economics, Janssen Pharmaceutical KK, 5-2, Nishi-kanda 3-chome

Chiyoda-ku, Tokyo 101-0065, Japan

${ }^{4}$ Düsseldorf Institute for Competition Economics (DICE), University of

Düsseldorf, Düsseldorf, Germany

Full list of author information is available at the end of the article
}

[10]. It was suggested that nearly $11 \%$ of people with RA experience suicidal thoughts, a statistic that rises to an alarming $30 \%$ in patients with a co-morbidity of depression [11]. Previous study found that people with comorbid RA and depression may use more health services and are less likely to adhere to their medication regimens $[12,13]$. A comorbidity of RA and depression is also associated with higher unemployment, work productivity losses, and increased healthcare costs to both individual patient and society $[13,14]$.

More often than not comorbid depression with RA is undiagnosed and therefore untreaeted [15] often because rheumatologists and their patients seldom communicate about depression [13, 16]. In the USA and Europe, the prevalence of depression was high in people with RA and the prevalence was found to be greater in younger patients [5]. Similar findings were found in only one Japanese study that identified factors associated with depression in female people with RA and found that among sociodemographic factors, "a decrease in the frequency of going out socially after having RA" and "a higher education" were significantly 
associated with depression [17]. However, evidence of depression in people with RA is limited in Asia studies and also Japan.

The present study was undertaken to determine the prevalence of depression in Japanese People with RA and explore the relationships between RA patient, depression and an array of demographic variables.

\section{Methods}

\section{Patient population and data collection}

A nationwide cross-sectional online survey was carried out in Japan during the months of July and August in 2016. The survey was national in its scope, drawing from a pool of more than 2000 people with RA. Figure 1 showed patient flow of this study. The study included 500 people with RA who had been diagnosed with RA for at least 1 year, whose current treatment scheme included at least one RA medication and completed all questionnaires.

The survey instrument contained questions about a variety of patient demographic characteristics such as age, gender, marital status, education, employment, and income. It also included questions covering clinical characteristics such as length of time since diagnosis, functional impairment as assessed using the Japanese version of the Stanford Health Assessment Questionnaire (J-HAQ score) [18], and the participant's current medical treatment scheme including whether biologic agents and conventional synthetic disease modifying anti-rheumatic drugs (conventional synthetic disease-modifying antirheumatic drugs; csDMARDs) are being used.

The Patient Health Questionnaire with 9 items (PHQ-9) was used to measure the presence and severity of depressive symptoms. The study used a Japanese language version of the PHQ-9 shown to be a valid screening tool to detect potential depression patients in Japanese hospitals [19]. In addition, the similar findings have been shown when using the PHQ-9 web-base and paper based survey [20]. The cut-off scores were defined as follows: no depression (0-4), mild (5-9), and moderate-to-severe $(\geq 10)$ [21].

\section{Statistical analysis}

Descriptive statistics were used to quantify baseline characteristics and depression condition while one-way analysis of variance was used to determine differences among relevant patient groupings. Ordered logistic regression was used to identify the determinants of depression conditions among survey respondents. We also reported univariate correlation coefficients between depression conditions and all other variables to assess associations of depression condition with each factor. In the multivariate model, all factors with $p$ values in the univariate analyses of $p<0.2$ were included (stepwise regression). All analyses were calculated using STATA version 14.0 (College Station, TX, USA). A $P$ value of $<0.05$ was considered statistically significant.

\section{Results}

\section{Patient demographics}

Data from a total of 500 patients with RA were included in the analysis. The mean age was 54.3 years old and $67 \%$ of the patients were female (Table 1 ).

\section{Depression prevalence}

Table 1 reveals the prevalence of depression among the 500 People with RA analyzed across a number of demographic characteristics. Overall, 176 (35\%) had depressive

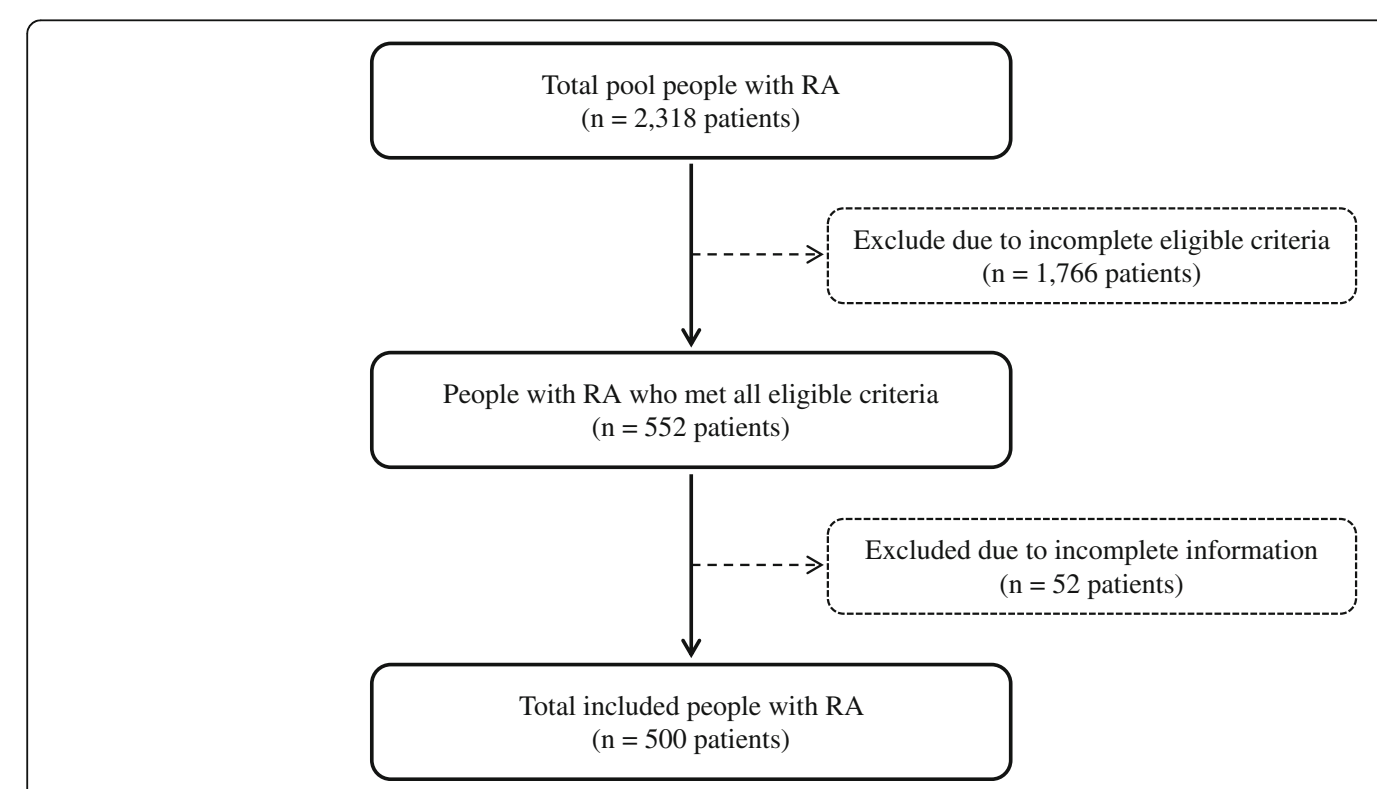

Fig. 1 Patient flow 
Table 1 Depression in RA patients analyzed by demographic characteristics

\begin{tabular}{|c|c|c|c|c|c|}
\hline Characteristics & Overall, N (\%) & No depression, N (\%) & Mild depression, N (\%) & $\begin{array}{l}\text { Moderate to severe } \\
\text { depression, } \mathrm{N}(\%)\end{array}$ & $P$-value \\
\hline Patients & 500 & $324(65)$ & $118(24)$ & $58(11)$ & \\
\hline Age $($ mean $\pm S D)$ & $54.28 \pm 10.02$ & $56.04 \pm 9.91$ & $51.57 \pm 10.02$ & $49.93 \pm 9.59$ & $<0.001$ \\
\hline$\leq 50$ years & $178(36)$ & $94(29)$ & $53(45)$ & $31(54)$ & \\
\hline $51-60$ years & $196(39)$ & $130(40)$ & $45(38)$ & $21(36)$ & \\
\hline$>60$ years & $126(25)$ & $100(31)$ & $20(17)$ & $6(10)$ & \\
\hline Gender & & & & & 0.036 \\
\hline Male & $163(33)$ & $118(37)$ & $28(24)$ & $17(29)$ & \\
\hline Female & $337(67)$ & $206(64)$ & $90(76)$ & $41(71)$ & \\
\hline Marital status & & & & & 0.004 \\
\hline Single & $97(19)$ & $49(15)$ & $34(29)$ & $14(24)$ & \\
\hline Married & $403(81)$ & $275(85)$ & $84(71)$ & $44(76)$ & \\
\hline Highest Education & & & & & 0.109 \\
\hline High school or less & $180(36)$ & $107(33)$ & $47(40)$ & $26(44)$ & \\
\hline College & $120(24)$ & $74(23)$ & $30(25)$ & $16(28)$ & \\
\hline Bachelor's degree or higher & $200(40)$ & $143(44)$ & $41(35)$ & $16(28)$ & \\
\hline Occupation & & & & & 0.141 \\
\hline Full-time & $164(33)$ & $112(34)$ & $36(30)$ & $16(28)$ & \\
\hline Part-time & $78(16)$ & $43(13)$ & $26(22)$ & $9(15)$ & \\
\hline Self-employed & $37(7)$ & $28(9)$ & $6(5)$ & $3(5)$ & \\
\hline Housewife & $141(28)$ & $89(27)$ & $33(28)$ & $19(33)$ & \\
\hline Retired & $20(4)$ & $18(6)$ & $1(1)$ & $1(2)$ & \\
\hline Unemployed & $57(11)$ & $32(10)$ & $16(14)$ & $9(15)$ & \\
\hline Other & $3(1)$ & $2(1)$ & $0(0)$ & $1(2)$ & \\
\hline \multicolumn{6}{|l|}{ Region } \\
\hline Hokkaido & $26(5)$ & $15(5)$ & $4(3)$ & $7(12)$ & 0.038 \\
\hline Tohoku & $23(5)$ & $17(5)$ & $4(3)$ & $2(3)$ & 0.645 \\
\hline Kanto & $230(46)$ & $147(45)$ & $53(46)$ & $30(52)$ & 0.646 \\
\hline Chubu & $63(13)$ & $45(14)$ & $10(8)$ & $8(14)$ & 0.303 \\
\hline Kansai & $95(19)$ & $58(18)$ & $30(25)$ & $7(12)$ & 0.073 \\
\hline Chugoku & $21(4)$ & $14(4)$ & $7(6)$ & $0(0)$ & 0.180 \\
\hline Shikoku & $11(2)$ & $6(2)$ & $2(2)$ & $3(5)$ & 0.259 \\
\hline Kyushu & $31(6)$ & $22(7)$ & $8(7)$ & $1(2)$ & 0.323 \\
\hline \multicolumn{6}{|l|}{ Annual individual income } \\
\hline$<3.7 \mathrm{M}$ Yen & $286(57)$ & $173(53)$ & $73(62)$ & $40(69)$ & 0.272 \\
\hline 3.7-7.7 M Yen & $105(21)$ & $74(23)$ & $22(19)$ & $9(15)$ & \\
\hline > $7.7 \mathrm{M}$ Yen & $45(9)$ & $34(11)$ & $7(6)$ & $4(7)$ & \\
\hline I don't know & $64(13)$ & $43(13)$ & $16(13)$ & $5(9)$ & \\
\hline Time since diagnosis (mean $\pm \mathrm{SD}$ ) & $10.67 \pm 8.63$ & $10.45 \pm 8.99$ & $11.07 \pm 8.07$ & $11.12 \pm 7.63$ & 0.242 \\
\hline$\leq 5$ years & $165(33)$ & $111(34)$ & $38(32)$ & $16(28)$ & \\
\hline $6-10$ years & $146(29)$ & $101(31)$ & $27(23)$ & $18(31)$ & \\
\hline$>10$ years & $189(38)$ & $112(35)$ & $53(45)$ & $24(41)$ & \\
\hline
\end{tabular}


Table 1 Depression in RA patients analyzed by demographic characteristics (Continued)

\begin{tabular}{|c|c|c|c|c|c|}
\hline Characteristics & Overall, N (\%) & No depression, N (\%) & Mild depression, N (\%) & $\begin{array}{l}\text { Moderate to severe } \\
\text { depression, } \mathrm{N}(\%)\end{array}$ & $P$-value \\
\hline \multicolumn{6}{|l|}{ Current Medication } \\
\hline Painkillers (NSAIDs/oral pain medication) & $80(16)$ & $39(12)$ & $27(23)$ & $14(24)$ & 0.005 \\
\hline Steroid & $110(22)$ & $66(20)$ & $29(25)$ & $15(26)$ & 0.481 \\
\hline DMARDs & & & & & 0.112 \\
\hline csDMARDs & $329(66)$ & $214(66)$ & $79(67)$ & $36(62)$ & \\
\hline csDMARDs + biologic agent & $113(23)$ & $65(20)$ & $30(25)$ & $18(31)$ & \\
\hline Biologic agent & $58(12)$ & $45(14)$ & $9(8)$ & $4(7)$ & \\
\hline \multicolumn{6}{|l|}{ Functional impairment } \\
\hline $\mathrm{J}$-HAQ score (mean $\pm \mathrm{SD})$ & $0.40 \pm 0.81$ & $0.26 \pm 0.55$ & $0.52 \pm 0.78$ & $0.98 \pm 1.50$ & $<0.001$ \\
\hline \multicolumn{6}{|l|}{ Comorbidity with depression } \\
\hline Depression & $25(5)$ & $7(2)$ & $6(5)$ & $12(21)$ & $<0.001$ \\
\hline \multicolumn{6}{|l|}{ Comorbidity other than depression } \\
\hline Hypertension & $79(16)$ & $52(16)$ & $16(14)$ & $11(19)$ & 0.638 \\
\hline High cholesterol & $42(8)$ & $24(7)$ & $11(9)$ & $7(12)$ & 0.458 \\
\hline Diabetes & $26(5)$ & $15(5)$ & $10(9)$ & $1(2)$ & 0.122 \\
\hline Migraines & $11(2)$ & $0(0)$ & $5(4)$ & $6(10)$ & $<0.001$ \\
\hline Heart condition & $8(2)$ & $3(1)$ & $2(2)$ & $3(5)$ & 0.060 \\
\hline Anxiety & $8(2)$ & $3(1)$ & $2(2)$ & $3(5)$ & 0.060 \\
\hline
\end{tabular}

$N$ number, \% percentage, SD standard deviation, $M$ Million, NSAID nonsteroidal anti-inflammatory drugs, RA rheumatoid arthritis, DMARDs disease modifying anti-rheumatic drugs, csDMARDs conventional synthetic disease modifying anti-rheumatic drugs, J-HAQ Japanese version of the Stanford Health Assessment Questionnaire

symptoms, whereas only 25 (5\%) had been officially diagnosed with depression or visited physicians due to depression, suggesting depression might be under-diagnosed or under-reported in people with RA.

The average age of patients with no depression based on self-report PHQ-9 assessment was 56.04 years. By comparison, the average age of patients with mild depression was 51.57 years, and that of patients with moderate to severe depression was 49.93 years, suggesting that younger people with RA are more susceptible to depression. Among people with RA, the majority of major depression patients were female and married. Comorbidity conditions, except for migraine and heart conditions (for example chronic heart failure and ischemic heart disease), were not different between patients with depression and those without.

Painkillers were taken more in patients with depression than in those without ( $23 \%$ vs $12 \%, P=0.005)$. No difference was found in treatment of steroid, csDMARDs and biologic agents.

Among the 324 patients who showed no signs of depression, the average J-HAQ score was 0.26 , whereas the score among those with mild depression was 0.52 and those with moderate to severe depression had an average J-HAQ score of $0.98(P<0.001)$, indicating that the greater physical disability patients experience greater depression.

\section{Determinant of depression among people with RA}

Table 2 shows the results of multivariable regression analysis for the determinants of depressive conditions among Japanese people with RA. A negative correlation with the prevalence of depression was found for age, meaning younger patients were more likely to experience depression, with a corresponding odds ratio (ORs) of 0.96 [95\% confidence interval (CI); 0.94-0.98]. Higher education was also negatively correlated with depression, meaning more education resulted in less depression (ORs, 0.61 (CI 0.381.00) for a bachelor's degree or higher. Another negative correlation was related to the biologic agent monotherapy (ORs, 0.36 (0.17-0.75)). People with RA with high J-HAQ score also had a high probability of developing depression (ORs 1.86: CI 1.40-2.48)). In summary, people with RA more likely to experience depression are those who are younger, less educated, have greater functional impairment, and who are treated with csDMARDs alone.

\section{Discussion}

The results of this study reveal that one third of Japanese people with RA might potentially have depression as assessed by PHQ-9 while only 5\% are officially diagnosed. Additionally, younger, less educated, more functionally impaired patients, and patients who are being treated with csDMARDs alone are more likely to 
Table 2 Determinants of depression among RA patients

\begin{tabular}{|c|c|c|c|c|}
\hline \multirow[t]{2}{*}{ Characteristics } & \multicolumn{2}{|l|}{ Univariate analysis } & \multicolumn{2}{|c|}{ Multivariate analysis } \\
\hline & ORs $(95 \% \mathrm{Cl})$ & $P$-value & ORs $(95 \% \mathrm{Cl})$ & $P$-value \\
\hline Age & $0.95(0.93-0.97)$ & $<0.001$ & $0.96(0.94-0.98)$ & 0.001 \\
\hline \multicolumn{5}{|l|}{ Gender (Reference: Male) } \\
\hline Female & $1.59(1.07-2.38)$ & 0.023 & $0.86(0.49-1.51)$ & 0.599 \\
\hline \multicolumn{5}{|l|}{ Marital status (Reference: Single) } \\
\hline Married & $0.52(0.34-0.80)$ & 0.003 & $0.68(0.40-1.17)$ & 0.168 \\
\hline \multicolumn{5}{|c|}{ Highest Education (Reference: High school or less) } \\
\hline College & $0.91(0.51-1.47)$ & 0.690 & $0.89(0.53-1.47)$ & 0.639 \\
\hline Bachelor's degree or higher & $0.57(0.38-0.87)$ & 0.010 & $0.61(0.38-1.00)$ & 0.050 \\
\hline \multicolumn{5}{|l|}{ Occupation (Reference: Full-time) } \\
\hline Part-time & $1.63(0.96-2.78)$ & 0.072 & $1.26(0.68-2.35)$ & 0.459 \\
\hline Self-employed & $0.70(0.31-1.58)$ & 0.396 & $0.85(0.35-2.06)$ & 0.725 \\
\hline Housewife & $1.28(0.81-2.05)$ & 0.289 & $1.09(0.59-2.00)$ & 0.781 \\
\hline Retired & $0.25(0.06-1.10)$ & 0.067 & $0.46(0.94-2.30)$ & 0.348 \\
\hline Unemployed & $1.69(0.93-3.08)$ & 0.086 & $1.14(0.55-2.37)$ & 0.728 \\
\hline Other & $1.60(0.12-19.85)$ & 0.715 & $1.48(0.08-25.86)$ & 0.787 \\
\hline \multicolumn{5}{|l|}{ Region } \\
\hline Hokkaido & $1.71(0.77-3.21)$ & 0.212 & & \\
\hline Tohoku & $0.64(0.25-1.65)$ & 0.361 & & \\
\hline Kanto & $1.10(0.77-1.59)$ & 0.584 & & \\
\hline Chubu & $0.75(0.42-1.34)$ & 0.333 & & \\
\hline Kansai & $1.09(0.70-1.71)$ & 0.692 & & \\
\hline Chugoku & $0.79(0.32-1.92)$ & 0.600 & & \\
\hline Shikoku & $1.88(0.57-6.19)$ & 0.296 & & \\
\hline Kyushu & $0.68(0.31-1.48)$ & 0.336 & & \\
\hline \multicolumn{5}{|l|}{ Annual individual income (Reference $<3.7$ M Yen) } \\
\hline 3.7-7.7 M Yen & $0.63(0.39-1.01)$ & 0.058 & $0.78(0.46-1.34)$ & 0.058 \\
\hline$>7.7 \mathrm{M}$ Yen & $0.50(0.24-1.03)$ & 0.059 & $0.75(0.31-1.79)$ & 0.059 \\
\hline \multicolumn{5}{|l|}{ Time since diagnosis (Reference: $\leq 5$ years) } \\
\hline $6-10$ years & $0.96(0.60-1.54)$ & 0.872 & $0.99(0.59-1.65)$ & 0.964 \\
\hline$>10$ years & $1.40(0.91-2.13)$ & 0.124 & $1.13(0.69-1.87)$ & 0.624 \\
\hline J-HAQ score & $2.01(1.59-2.53)$ & $<0.001$ & $1.86(1.40-2.48)$ & $<0.001$ \\
\hline \multicolumn{5}{|l|}{ Comorbidity } \\
\hline Hypertension & $0.99(0.60-1.64)$ & 0.986 & & \\
\hline High cholesterol & $1.46(0.78-2.72)$ & 0.233 & & \\
\hline Diabetes & $1.15(0.54-2.45)$ & 0.716 & & \\
\hline Migraines & $13.23(4.29-40.81)$ & $<0.001$ & $9.27(0.99-32.19)$ & 0.087 \\
\hline Heart condition & $3.84(1.01-14.61)$ & 0.048 & $4.18(0.95-18.30)$ & 0.058 \\
\hline Anxiety & $3.84(1.01-14.61)$ & 0.048 & $2.20(0.47-10.27)$ & 0.317 \\
\hline \multicolumn{5}{|l|}{ Current medication } \\
\hline Pain killer (NSAIDs/oral pain medication) & $2.11(1.34-3.34)$ & 0.001 & $1.60(0.94-2.72)$ & 0.084 \\
\hline Steroid & $1.30(0.85-1.98)$ & 0.228 & & \\
\hline \multicolumn{5}{|l|}{ DMARDs (Reference: csDMARDs) } \\
\hline csDMARDs + biologic agent & $1.40(0.92-2.15)$ & 0.117 & $0.82(0.49-1.37)$ & 0.459 \\
\hline Biologic agent & $0.54(0.28-1.05)$ & 0.067 & $0.36(0.17-0.75)$ & 0.007 \\
\hline
\end{tabular}

Bold numbers indicate significance. Univariate analysis: significant $p$ value $<0.2$, multivariate analysis (stepwise approach): significant value $=0.05$. ORs odds ratio, $C l$ confidence interval, $R A$ rheumatoid arthritis, $M$ Million, NSAID nonsteroidal anti-inflammatory drugs, DMARDs disease modifying anti-rheumatic drugs, csDMARDs conventional synthetic disease modifying anti-rheumatic drugs, J-HAQ Japanese version of the Stanford Health Assessment Questionnaire 
have depressive syptoms. These findings are important to increase awareness of rheumatologist regarding depression. Furthermore, the results call for multidisciplinary treatment teams that do not only focus on the treatment of physical symptoms but also take into account a patient's psychological condition. This approach will bring together the skills and knowledge of all team members which may may comprise case managers, pharmacists, physical and occupational therapists, social workers, physiatrists, orthopedists, or other health professionals to assess and manage care for the individual patient's needs [22].

The key finding of this study is that a potential significant under-reporting of depression among Japanese people with RA might exist. The prevalence of depression among people with RA has been reported in previous studies worldwide [5], ranging from $15 \%$ up to $39 \%$, and our finding of $35 \%$ by PHQ-9 is consistent with those results. Severe depressive symptom (PHQ $\geq 10$ ) was less frequent in this study (11\%) than the frequency reported in Asians and Pacific Islanders reported in 2009 (36\%), which might be due to the development of treatment along with less physical functional impairment. However, there was still discrepancy in the prevalence between PHQ-9 and the official diagnosis. One explanation of the underreporting of depression might be related to Asian cultural factors. People in Asian societies such as China and Japan are less likely to speak openly about depression due to the stigma attached to it as well as the need to maintain perceived strength of character [23]. However, differences in prevalence can be found when using different measurement instruments. For example, the point prevalence of major depressive disorders in Japanese people with RA was $6.8 \%$ when using the Mini-International Neuropsychiatric Interview [24]. This observation makes it the more important for physicians and all healthcare professional who are members of multidisciplinary team in Asia to be highly attuned to potential depression when treating their people with RA.

In this study, people with comorbid RA and depression tended to be younger than people without depression. This comparison is evident as well in the national Japanese survey conducted by the Ministry of Health, Labor, and Welfare in 2014 [25] and an Japanese employee survey conducted by the Northern-Japan Occupational Health Promotion Centers Collaboration Study for Mental Health [26]. Additionally, the results of the present study showed a positive association between depression and migraine and heart condition comorbidities. Several studies reported the relationship of depression with cardiovascular disease [27, 28], which is well known to be correlated with RA [29, 30].

Several studies show a positive correlation between depression and RA disease activity scores such as disease activity score for 28-joint (DAS28) or clinical disease activity index (CDAI) [31, 32]. Although the current study did not measure disease severity by such composite measures due to the limitations of online survey, people with RA were asked to rate their functional disability using J-HAQ [18], which closely correlates to both DAS28 and CDAI [33]. The results indicate that a higher J-HAQ score was correlated with depression. J-HAQ can measure a variety of functional limitations caused not only by inflammatory disease activity but also by joint damage and long-term disability. The resulting loss of valued activities has been shown to be a strong predictor of depression in patients with RA [13, 34]. Additionally, systemic inflammation that also causes functional disability is associated with, causes, or contributes to depressive symptoms experienced during the course of disorders that include chronic inflammation [35]. Patients with major depression have increased Interleukin 6 (IL-6) [36]. concentrations and pro-inflammatory tumor necrosis factor-alpha (TNF- $\alpha$ ) [37] in serum, plasma, or both. A recent meta-analysis showed raised inflammatory markers such as IL-6 or C-reactive protein (CRP) are significantly associated with the subsequent development of depressive symptoms, which supports the hypothesis that there is an association between the inflammation and depression [38]. Consequently, medications that result in lower IL- 6 and TNF- $\alpha$ level might have a direct positive impact on treating depression. Our findings also showed that patients receiving biologic agents had lower probability of developing depression compared to patients treated with csDMARDs alone, which can also be explained by the mechanism of the reduction of cytokine level that might be linked to depression [38-40]. These findings suggest that further research on the connection between biologic treatment and depression is needed.

There were several limitations to the present study. First, the analysis was based on a cross-sectional survey. As this was a single sample, the study was unable to demonstrate a causal relationship or account for changes in perception that might occur over time. Second, the study did not show that the documented depression condition was the direct consequence of the patient's RA condition - other factors in patients' lives could be the cause. Third, the exact disease activity was not completely known because this was an online survey consisting of patients reports. This hampered the analysis for the direct relationship between disease activity and depression. Furthermore, this was an online survey which might not be representative of the overall Japanese RA population. Usually, people that are more familiar with the Internet take part in online surveys which are in turn younger and probably better educated. On the other hand, the average age of our sample (54.28 years) does not differ much from a recent Japanese claims database analysis with more than 16,000 RA patients [41]. In that study the average patient age was 53.96 years which makes us believe that the potential selection bias in our 
sample is low. Last, there is a possibility of diagnostic overshadowing if some physical symptoms of RA are misattributed to depression. An example is feeling tired or having little energy which are both symptoms of depression as well as RA. This can potentially lead to an overestimation of depression in RA.

\section{Conclusions}

In conclusion, the results of this study suggest that depression among Japanese people with RA is potentially under-reported and under-diagnosed. Rheumatologists should take particular care in assessing the psychological status of people with RA, particularly those susceptible to depression -younger patients, patients with greater functional impairment, and patients with a treatment regimen of csDMARDs alone.

\section{Additional file}

Additional file 1: Reviewer reports and $A U$ response to reviewers. (DOCX $18 \mathrm{~kb})$

\section{Abbreviations}

CDAl: Clinical disease activity index; Cl: Confidence interval; CRP: C-reactive protein; csDMARDs: Conventional synthetic disease modifying anti-rheumatic drugs; DAS28: Disease activity score for 28-joint; DMARDs: Disease modifying anti-rheumatic drugs; IL-6: Interleukin 6; J-HAQ: Japanese version of the Stanford Health Assessment Questionnaire; ORs: Odds ratio; PHQ-9: The Patient Health Questionnaire with 9 items; RA: Rheumatoid arthritis; TNFa: Tumor necrosis factor-alpha

\section{Acknowledgements}

We would like to thank Medilead, Inc. to identify patients and also collected all questionnaires.

We wish to thank those who reviewed the manuscript for their constructive comments (Additional file 1).

\section{Funding}

We received funding from Janssen pharmaceutical KK to conduct the survey. The study design, data collection, data analysis, data interpretation, and writing of the report, was solely done by the authors. The findings and conclusions in this report do not necessarily reflect the views of Janssen Pharmaceutical KK.

\section{Availability of data and materials}

The dataset supporting the conclusions is not publicly available. Interested readers can contact directly $\mathrm{JM}$.

\section{Authors' contributions}

JM, YK and RS made substantial contributions to conception and design, and interpretation of data; RS performed the analysis; JM was drafting the manuscript; JM, YK and RS discussed for critical important intellectual content; JM has given final approval of the version to be published. All authors read and approved the final manuscript.

\section{Ethics approval and consent to participate}

This article is based on a web-based survey and does not involve any interventions conducted on human subjects by any of the authors. The authors were not involved in the collection of this data. Data were collected by the database provider and patients were informed that their data would be used for research (opt-out system). Data were de-identified before addition to the database. The study was performed in accordance with the guidelines of Johnson \& Johnson and was approved by its approval committee.
Consent for publication

Not applicable.

\section{Competing interests}

JM and RS are employed at Janssen Pharmaceutical KK, YK has received lecture fees from AbbVie, Eisai Pharmaceutical, Chugai Pharmaceutical, Bristol Myers Squibb, Astellas Pharmaceutical, Mitsubishi Tanabe Pharma Corporation, Pfizer, Janssen, and UCB.

\section{Publisher's Note}

Springer Nature remains neutral with regard to jurisdictional claims in published maps and institutional affiliations.

\section{Author details}

${ }^{1}$ Health Economics, Janssen Pharmaceutical KK, 5-2, Nishi-kanda 3-chome Chiyoda-ku, Tokyo 101-0065, Japan. ${ }^{2}$ Center of Pharmaceutical Outcomes Research, Naresuan University, Phitsanulok, Thailand. ${ }^{3}$ Division of Rheumatology, Department of Internal Medicine, Keio University School of Medicine, Tokyo, Japan. ${ }^{4}$ Düsseldorf Institute for Competition Economics (DICE), University of Düsseldorf, Düsseldorf, Germany.

Received: 30 May 2017 Accepted: 19 October 2017 Published online: 28 November 2017

\section{References}

1. Dickens C, McGowan L, Clark-Carter D, Creed F. Depression in rheumatoid arthritis: a systematic review of the literature with meta-analysis. Psychosom Med. 2002;64(1):52-60.

2. Löwe B, Willand L, Eich W, Zipfel S, Ho AD, Herzog W, Fiehn C. Psychiatric comorbidity and work disability in patients with inflammatory rheumatic diseases. Psychosom Med. 2004;66(3):395-402.

3. Isik A, Koca SS, Ozturk A, Mermi O. Anxiety and depression in patients with rheumatoid arthritis. Clin Rheumatol. 2007:26(6):872-8.

4. Bruce TO. Comorbid depression in rheumatoid arthritis: pathophysiology and clinical implications. Curr Psychiatry Rep. 2008;10(3):258-64.

5. Matcham F, Rayner L, Steer S, Hotopf M. The prevalence of depression in rheumatoid arthritis: a systematic review and meta-analysis. Rheumatology (Oxford). 2013;52(12):2136-48.

6. Tektonidou MG, Dasgupta A, Ward MM. Suicidal ideation among adults with arthritis: prevalence and subgroups at highest risk. Data from the 2007-2008 National Health and nutrition examination survey. Arthritis Care Res. 2011;63(9):1322-33.

7. Treharne GJ, Hale ED, Lyons AC, Booth DA, Banks MJ, Erb N, Douglas KM, Mitton DL, Kitas GD. Cardiovascular disease and psychological morbidity among rheumatoid arthritis patients. Rheumatology (Oxford). 2005;44(2): 241-6.

8. Scherrer JF, Virgo KS, Zeringue A, Bucholz KK, Jacob T, Johnson RG, True WR Carney RM, Freedland KE, Xian $\mathrm{H}$, et al. Depression increases risk of incident myocardial infarction among veterans administration patients with rheumatoid arthritis. Gen Hosp Psychiatry. 2009:31(4):353-9.

9. Ang DC, Choi H, Kroenke K, Wolfe F. Comorbid depression is an independent risk factor for mortality in patients with rheumatoid arthritis. J Rheumatol. 2005;32(6):1013-9.

10. Gettings L. Psychological well-being in rheumatoid arthritis: a review of the literature. Musculoskeletal Care. 2010:8(2):99-106.

11. Treharne GJ, Lyons AC, Kitas GD. Suicidal ideation in patients with rheumatoid arthritis. Research may help identify patients at high risk. BMJ. 2000;321(7271):1290

12. Mattey DL, Dawes PT, Hassell AB, Brownfield A, Packham JC. Effect of psychological distress on continuation of anti-tumor necrosis factor therapy in patients with rheumatoid arthritis. J Rheumatol. 2010;37(10):2021-4.

13. Margaretten $M$, Julian $L$, Katz $P$, Yelin E. Depression in patients with rheumatoid arthritis: description, causes and mechanisms. Int J Clin Rheumtol. 2011;6(6):617-23.

14. Li $\mathrm{X}$, Gignac MA, Anis AH. The indirect costs of arthritis resulting from unemployment, reduced performance, and occupational changes while at work. Med Care. 2006;44(4):304-10

15. Nagyova I, Stewart RE, Macejova Z, van Dijk JP, van den Heuvel WJ. The impact of pain on psychological well-being in rheumatoid arthritis: the mediating effects of self-esteem and adjustment to disease. Patient Educ Couns. 2005;58(1):55-62. 
16. Sleath B, Chewning B, de Vellis BM, Weinberger M, de Vellis RF, Tudor G, Beard A. Communication about depression during rheumatoid arthritis patient visits. Arthritis Rheum. 2008;59(2):186-91.

17. Takeda T, Morimoto N, Kinukawa N, Nagamine R, Shutou T, Tashiro N. Factors affecting depression and anxiety in female Japanese patients with rheumatoid arthritis. Clin Exp Rheumatol. 2000;18(6):735-8.

18. Matsuda Y, Singh G, Yamanaka H, Tanaka E, Urano W, Taniguchi A, Saito T, Hara M, Tomatsu T, Kamatani N. Validation of a Japanese version of the Stanford health assessment questionnaire in 3,763 patients with rheumatoid arthritis. Arthritis Rheum. 2003;49(6):784-8.

19. Suzuki K, Kumei S, Ohhira M, Nozu T, Okumura T. Screening for major depressive disorder with the patient health questionnaire (PHQ-9 and PHQ2) in an outpatient clinic staffed by primary care physicians in Japan: a case control study. PLoS One. 2015;10(3):e0119147.

20. Bot AGJ, Menendez ME, Neuhaus V, Mudgal CS, Ring D. The comparison of paper- and web-based questionnaires in patients with hand and upper extremity illness. Hand (N Y). 2013:8(2):210-4.

21. Saijo Y, Chiba S, Yoshioka E, Kawanishi Y, Nakagi Y, Itoh T, Sugioka Y, Kitaoka-Higashiguchi K, Yoshida T. Effects of work burden, job strain and support on depressive symptoms and burnout among Japanese physicians. Int J Occup Med Environ Health. 2014:27(6):980-92.

22. Marion CE, Balfe LM. Potential advantages of Interprofessional Care in Rheumatoid Arthritis. J Manag Care Pharm. 2011;17(9 Suppl B):S25-9.

23. Margaretten M, Yelin E, Imboden J, Graf J, Barton J, Katz P, Julian L. Predictors of depression in a multiethnic cohort of patients with rheumatoid arthritis. Arthritis Rheum. 2009;61(11):1586-91.

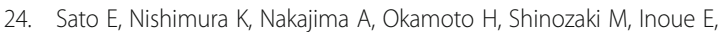
Taniguchi A, Momohara S, Yamanaka H. Major depressive disorder in patients with rheumatoid arthritis. Mod Rheumatol. 2013;23(2):237-44.

25. Statistics and Information Department Minister's Secretariat Ministry of Health Labour and Welfare. Patient survey 2014. Tokyo: Health and Welfare Statistics Association; 2016.

26. Fushimi M. Prevalence of depressive symptoms and related factors in Japanese employees: a comparative study between surveys from 2007 and 2010. Psychiatry J. 2015;2015(Article ID 537073):7.

27. Hare DL, Toukhsati SR, Johansson P, Jaarsma T. Depression and cardiovascular disease: a clinical review. Eur Heart J. 2014;35(21):1365-72.

28. Watson K, Summers KM. Depression in patients with heart failure: clinical implications and management. Pharmacotherapy. 2009;29(1):49-63.

29. Liu YL, Szklo M, Davidson KW, Bathon JM, Giles JT. Differential Association of Psychosocial Comorbidities with Subclinical Atherosclerosis in rheumatoid arthritis. Arthritis Care Res (Hoboken). 2015;67(10):1335-44.

30. Kaplan MJ. Cardiovascular complications of rheumatoid arthritis assessment, prevention and treatment. Rheum Dis Clin N Am. 2010;36(2): 405-26.

31. Kekow J, Moots R, Khandker R, Melin J, Freundlich B, Singh A. Improvements in patient reported outcomes, symptoms of depression and anxiety, and their association with clinical remission among patients with moderate-tosevere active early rheumatoid arthritis. Rheumatology (Oxford). 2011;50(2): 401-9.

32. Lee YC, Frits ML, lannaccone CK, Weinblatt ME, Shadick NA, Williams DA, Cui J: Subgrouping of rheumatoid arthritis patients based on pain, fatigue, inflammation and psychosocial factors. Arthritis \& rheumatology. Arthritis Rheumatol. 2014, 66(8):2006-2014

33. Salaffi F, Cimmino MA, Leardini G, Gasparini S, Grassi W. Disease activity assessment of rheumatoid arthritis in daily practice: validity, internal consistency, reliability and congruency of the disease activity score including 28 joints (DAS28) compared with the Clinical Disease Activity Index (CDAI). Clin Exp Rheumatol. 2009;27(4):552-9.

34. Covic T, Adamson B, Spencer D, Howe G. A biopsychosocial model of pain and depression in rheumatoid arthritis: a 12-month longitudinal study. Rheumatology (Oxford). 2003;42(11):1287-94.

35. Miller $\mathrm{AH}$, Maletic $\mathrm{V}$, Raison CL. Inflammation and its discontents: the role of cytokines in the pathophysiology of major depression. Biol Psychiatry. 2009; 65(9):732-41.

36. Alesci S, Martinez PE, Kelkar S, Ilias I, Ronsaville DS, Listwak SJ, Ayala AR, Licinio J, Gold HK, Kling MA, et al. Major depression is associated with significant diurnal elevations in plasma interleukin-6 levels, a shift of its circadian rhythm, and loss of physiological complexity in its secretion: clinical implications. J Clin Endocrinol Metab. 2005:90(5):2522-30.
37. Kahl KG, Greggersen W, Rudolf S, Stoeckelhuber BM, Bergmann-Koester CU, Dibbelt L, Schweiger U. Bone mineral density, bone turnover, and osteoprotegerin in depressed women with and without borderline personality disorder. Psychosom Med. 2006;68:669-74.

38. Valkanova V, Ebmeier KP, Allan CL. CRP, IL-6 and depression: a systematic review and meta-analysis of longitudinal studies. J Affect Disord. 2013; 150(3):736-44.

39. Wang D, Sun Y, Salvadore G, Singh J, Hsu B, Curran M, Caers I, Kent J, Drevets WC, Wittenberg GM, et al. P.2.h.016 Interleukin-6 antibody Sirukumab improves depressive symptoms in a randomized, placebocontrolled, phase 2 study in patients with rheumatoid arthritis. Eur Neuropsychopharmacol. 2015;25(Supplement 2):S462.

40. Yarlagadda A, Alfson E, Clayton AH. The blood brain barrier and the role of cytokines in neuropsychiatry. Psychiatry (Edgmont). 2009;6(11):18-22.

41. Mahlich J, Sruamsiri R. Treatment patterns of rheumatoid arthritis in Japanese hospitals and predictors of the initiation of biologic agents. Curr Med Res Opin. 2017:3(1):101-7.

\section{Submit your next manuscript to BioMed Central and we will help you at every step:}

- We accept pre-submission inquiries

- Our selector tool helps you to find the most relevant journal

- We provide round the clock customer support

- Convenient online submission

- Thorough peer review

- Inclusion in PubMed and all major indexing services

- Maximum visibility for your research

Submit your manuscript at www.biomedcentral.com/submit

) Biomed Central 